\title{
HIGHER EDUCATION AND PUBLIC POLICY
}

\author{
Ms. Prerna Pandya
}

\begin{abstract}
The Indian higher education system is facing a crisis that is affecting its ability to build world class higher education institutions. Indians have the ability to cope up with that crisis but sometimes they fail to do so because of the 'EDUCATION SYSTEM'. This paper will focus on issues and challenges related to quality, access and integrity of the higher education system in India.The government is responsible for the overall development of the basic infrastructure of Higher Education sector, both in terms of policy and planning. The combination of these two will expand the access and quality improvement in the Higher Education, through world class Universities, Colleges and other Institutions. The paper will throw light on the Vision, Mission, Objectives and Functions for making Higher Education peculiar by using public policies.
\end{abstract}

\section{Introduction:}

Concerning students, higher education system of India is the world's third largest, next to China and the United States. However, India has adopted English as primary language for higher education and research. University Grants Commissioner runs all institutes as well universities in India. There are number of institutes affiliated to UGC.

Below mentioned table is showing information ofuniversities which are affiliated to UGC:

Totalnumber of Universities in the country as on 22.02.2017

\begin{tabular}{|c|c|}
\hline University & Total No. \\
\hline State University & 359 \\
\hline Deemed to be University & 123 \\
\hline Central University & 47 \\
\hline Private University & 260 \\
\hline
\end{tabular}




\begin{tabular}{|l|c|}
\hline Total & 789 \\
\hline
\end{tabular}

In short there is no bound in places to acquire knowledge for students. In various universities variegated curriculum is taught. Although,Indian's spend nearly billions of amounts annually to let their children learn abroad for higher studies and technical practices while there is no reason for India not emerging as a global hub for higher education and technical practices. So the major issue is augmentation of potential in higher education to retain the curl of rising indigenous and universal wish.

\section{Pitfalls:}

Let's have a look upon some points which are really responsible for above scenario:

1. Selection of field:Now-a-days it has been continuously observed that students enrol for higher studies with a different perspective of being a blind follower. They sometimes don't think about the field of their own choice. As we know in Indian families, mostly foremost decisions like study, career, job, marriage, etc. are taken by elders of that family. That is also one of the problem students are forced to select the field for their studies. One major issue is with pupils themselves as they unable to find their own capabilities and blindly follow their friends or classmates without any knowledge of the field whether they will be able to shape themselves in right direction afterwards.

2. Lack of interest: Pupils don't have that much interest in higher studies. The reason is they are quite aware about employment scenario. In India there are fewer chances to get a well settled job for every pupil who gets his higher education done. They have the mindset if after studying up to higher level education they are unable to get their dreamt job or outcome it all goes in vain. It happens vice-versa also they don't pay that much attention to study because they don't understand the seriousness of it at the time \& pass their time that realizes them in future.

3. Curriculum design:As in India there are various universities shown above in the table there is a vast and differed curriculum among all universities affiliated to UGC. It's truly good to have a vast and unique curriculum. But the stumbling block in our higher education system is we concentrate more upon theatrical teaching only not on practical teaching. Because of this system students are unable to pop up with practical in real life.

4. Deficiency in infrastructure:An observation says institutions affiliated to UGC are not built as per UGC requirement. Infrastructure of an institution must be well equipped. Well established laboratories, a huge playground, garden area, facilitated class rooms, sick room with needed first-aid,and workshop with required instruments, a spacious and clean cafeteria, etc. These fall under initial infrastructure of an institute. College infrastructure should be pleasant and enthusiast for teachinglearning process.

5. Enrolling of low grade students: In UGC affiliated colleges it was a scenario earlier student who had scored $45 \%$ of result they could only enrol for higher education in 
miscellaneous field like agriculture, law, management, medicine or engineering. The current drawback is pupil can easily get enrol in these field only with $35 \%$ of lowgrade. As an outcome of this Institutes are getting very weak students those who have the mindset if they will not study sincerely as well with good grade still they can get enrolled with an ease for other higher education or acquire a job.

6. Paucity in inputs:so many colleges in India there is no stipulated staff fulfilled. In few colleges only quality education is being shared. Moreover, it happens vice-versa that colleges also obtain inadequate pupils.

\section{Survey was done on Higher Education in world, and it is showingWorld University Rankings 2016-2017:}

India's leading university - the Indian Institute of Science, Bangalore - is edging closer to the top 200, its highest ever position. The University of Oxford has become the first UK University to top the Times Higher Education.It bangs the five-time leader, the California Institute of Technology, into second place in the World University Rankings 20162017.Chinese University of Hong Kong and Korea Advanced Institute of Science and Technology (KAIST)) fall in top 100 while City University of Hong Kong, University of Science and Technology of China, Fudan University and Hong Kong Polytechnic University fall in top 200.

Moreover, China's two flagship universities have acquired - Peking University falls the top 30 at 29th (up from 42nd last year), while Tsinghua University falls the top 40 at 35th (up from joint 47th). Asia's the National University of Singapore, is at 24th - its highest ever rank.

Figures mentioned above reflect status of India for higher education.

\section{Antidote:}

Let me elucidate you with a few antidotes which are fundamental simultaneously paramount for higher education system.

- The student should be guided by their parents as well teachers for specific field in which they have opportunity of making sound career. They should not be forced to choose the field. Parents must have to give them chance to try out their own interested field. So that pupils can prove their capabilities in their choice field and make a better future.

- To bring more employment in India government must try in a right direction. Government should start small-term internships to provide mock experience so they can face the reality of job sectors. Government must widen the scope of employment by establishing MNCs, BPOs, Firms, and a lot other Private and Public Sector companies for the benefit of India. Let parents also make pupils be aware about the importance of higher education and career as well. Pupils of today are the future of India so they must be mature enough to study well and utilise their own time in a proper way.

- In India, mostly in various institutions as well in field theatrical curriculum is only focused. There is no practical curriculum implemented. The remedy for this can be a 


\section{Ms. Prerna Pandya / Page 88-92}

curriculum which is influenced more by practical teaching must be designed and implemented. To make this practice a reality institutes must be well equipped. All those instruments which are required for practical must be purchased, arranged properly in institutes. Faculty also must be given training to run and maintain the instruments.

- Institute should be built as per the UGC norms of infrastructure. And UGC should take actions against those institutes which are not established as per the norms and students are suffering with requisites even in the institutes.

- UGC must again implement the rule of enrolling students who have scored $45 \%$ of result. In this manner institutes will have qualitative pupils who really want to work hard for studies and make their bright career.

- Colleges must have advanced and studious staff who can easily pop up with students. They must be facilitated as per GTU norms. So that they give their best to pupils. They must be given some freedom to work and environment.

If these above remedies will be implemented then scenario of higher education will be enhanced. Major parameters in sequence for betterment of higher education are mentioned below in the Higher education architecture.

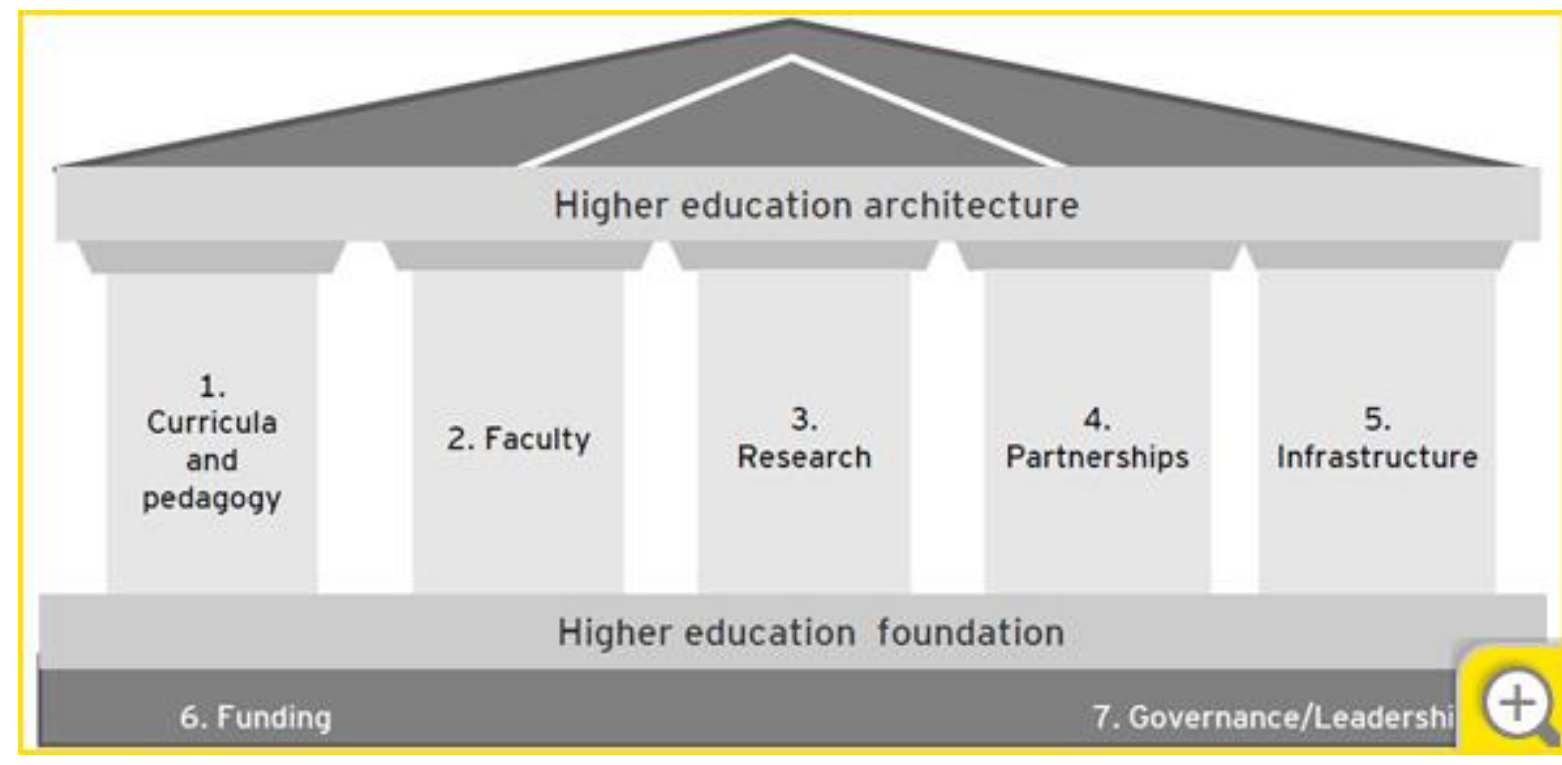

\section{Conclusions:}

There will be change in Indian higher education if all parameters like pupils, parents, faculty, institutes, and government work together for betterment of India. Mission of getting India educated at higher level also can be reached through implementing beneficiary remedies. If planning of curriculum and employment is done properly then automatically quality will be improved. 
Towards Excellence: An Indexed, Refereed \& Peer Reviewed Journal of Higher Education / Ms. Prerna Pandya / Page 88-92

\section{References:}

www.highereducation.org

http://www.unesco.org/education/pdf/24_235.pdf

http://ftp.iza.org/dp3827.pdf

\section{Ms. Prerna Pandya}

Assistant professor,

Silver Oak College of Engineering and Technology

E-Mail: prernapandya.gn@ socet.edu.in

M- 09173015194 